"The relationship between the waste recycling fee and subsidy of due recyclable waste"

\begin{tabular}{|c|c|c|}
\hline AUTHORS & \multicolumn{2}{|l|}{ Wei-Lung Huang } \\
\hline ARTICLE INFO & \multicolumn{2}{|c|}{$\begin{array}{l}\text { Wei-Lung Huang (2016). The relationship between the waste recycling fee and } \\
\text { subsidy of due recyclable waste. Environmental Economics, } 7(1), 67-75 \text {. doi: } \\
10.21511 / \text { ee.07(1).2016.09 }\end{array}$} \\
\hline DOI & \multicolumn{2}{|c|}{ http://dx.doi.org/10.21511/ee.07(1).2016.09 } \\
\hline RELEASED ON & \multicolumn{2}{|l|}{ Thursday, 24 March 2016} \\
\hline JOURNAL & \multicolumn{2}{|l|}{ "Environmental Economics" } \\
\hline FOUNDER & \multicolumn{2}{|c|}{ LLC "Consulting Publishing Company "Business Perspectives" } \\
\hline & & $\begin{array}{l}\text { ニE: } \\
\text { =E: }\end{array}$ \\
\hline NUMBER OF REFERENCES & NUMBER OF FIGURES & NUMBER OF TABLES \\
\hline 0 & 0 & 0 \\
\hline
\end{tabular}

C The author(s) 2022. This publication is an open access article. 
Wei-Lung Huang (Taiwan)

\title{
The relationship between the waste recycling fee and subsidy of due recyclable waste
}

\begin{abstract}
This study employs a life-cycle evaluation model of due recyclable waste (DRW) to analyze its optimal waste recycling fee (WRF) and subsidy. The results suggest that the government could set the optimal WRF and subsidy of DRW under the assumptions of the relationship that exist between the WRF and the subsidy for the budgetary constraints, but not set for the externality of DRW, and the environmental consciousness of individuals. And the different purposes of the WRF and subsidy are the reasons why a life-cycle evaluation model of due recyclable waste (DRW) is necessary to analyze its optimal waste recycling fee (WRF) and subsidy.
\end{abstract}

Keywords: life-cycle evaluation model, waste recycling fee, subsidy, due recyclable waste.

JEL Classification: Q53.

\section{Introduction}

Many countries have used a waste recycling fee (WRF) and subsidy to promote the recycling systems of due recyclable waste (DRW). For example, the 1986 California Beverage Container Recycling and Litter Reduction Act required manufacturers of most beverage containers to pay a fee per container to a state-managed recycling fund. When containers are returned, the fund makes a payment per container to the individual or organization collecting the container. In the Flemish region of Belgium, a combination of diversion policy instruments (disposal waste levy, separate collection targets for all public authorities, and pay-as-you-throw schemes and subsidies) for separate collection schemes have produced a higher rate (216 kilograms per capita in 2004) of total separately collected biodegradable municipal waste (BMW) compared to Estonia, Finland, Germany, Hungary and Italy $^{1}$ (see EEA, 2009; ETC/RWM, 2008; and Naughton et al., 1990).

A relationship between the WRF and the subsidy pertaining to DRW (here termed the Specific Relation) must be set by the government for the budgetary constraints, but few studies have analyzed the appropriateness of the specific relation. And the specific relation in Taiwan is that its present (2012) subsidy is equal to $4 / 3$ times its WRF. From Gupt and Sahay (2015), "Recycling fee combined within recycling subsidy" is one of the most common economic instruments in OECD countries, and it uses

\footnotetext{
(C) Wei-Lung Huang, 2016.

Wei-Lung Huang, Assistant Professor and Chairman, Finance, China University of Science and Technology, Taiwan.

1 Taiwan's Environmental Protection Administration has classified DRW containers as containers composed of iron, aluminum, glass, paper (aseptic cartons, paper cartons and paper tableware), and plastic (PET, PVC, PE, PP, PS form and PS non-form) and pesticide containers. DRW commodities include general batteries, automobiles, motorcycles, tires, lead-acid batteries, lubricants, electronics (laptops, cases, motherboards, monitors, hard disks, printers, power supplies and keyboards), household appliances (televisions, washing machines, refrigerators, air conditions and fans) and light bulbs.
}

the revenue from Advanced recycling fee (or postconsumption recycling fee) to subsidize the cost from the waste management (or upstream producer's activity to reduce, reuse or recycle). The most common economic instruments in OECD countries are Advanced recycling fee, Recycling fee combined within recycling subsidy, Deposit refund system (DRS), and two types of upstream taxes (Material taxes and Upstream combined tax/subsidy) (see Walls, 2006; and 2011; and Nnorom and Osibanjo, 2008).

For the major question of the specific relation should be the different purposes of the WRF and subsidy are focused on the externalities posed by the different stage of DRW, from the perspective of the life cycle of DRW. The purposes of the WRF are focused on the waste stage of DRW to internalize the external cost of the wasted DRW. The purposes of the subsidy are focused on the recycled material stage of DRW to promote the resource recycling program, to internalize the external benefit of recyclable resources $^{2}$ (see Hodge et al., 2010; and Moore and Scott, 1983).

This paper thus introduces the function of the specific relation and then explores a life-cycle-based evaluation of the government's welfare maximization using WRF and subsidy with and without the externality of DRW. Cheng et al. (2009) employed an optimal control model (modeling a dynamic relationship between the recycled containers and the products) to discuss the effects of the beverage container recycling policy in Taiwan. Yeh and Shaw

\footnotetext{
${ }^{2}$ The purposes of the WRF are to internalize the external cost of the wasted DRW, reduce the sales (waste) weight of DRW and balance subsidy payments. The purposes of the subsidy are to promote the resource recycling program, and to internalize the external benefit of recyclable resources. The other points of the WRF and subsidy are the costs derived from littering and disposal, the loss of consumer surplus due to price increases, the resource costs of delivery, the consumer inconvenience costs incurred when using recycling DRW, the savings in energy and natural resources, the skilled jobs, the greenhouse gas emissions (see Hodge et al., 2010; Porter, 1983; and Moore and Scott, 1983).
} 
(2004) used an economic model to discuss the performance bond system for the management of hazardous wastes. Huang (2001) used an economic model to discuss the crowding-out effect of subsidies in motorcycle-tire and car-tire recycling. Kulshreshtha and Sarangi (2001) analyzed a model with and without the external benefit of recycling and found that the model without the external benefit of recycling could be viewed as a model of coupons or mail-in rebates (as devices of price discrimination).

This paper is organized as follows. Section 1 develops a model for the government's welfare maximization through the use of the WRF and subsidy without the externality of DRW. Section 2 develops a model of the government's welfare maximization of WRF and subsidy with the externality of DRW. The final section offers conclusions.

\section{The model without the externality of DRW}

Because the WRF and subsidy are at different stages of the life cycle of DRW, we constructed a model of the life cycle of DRW. Kleineidam et al. (2000) used the control theory to discuss effective chain management for production chains such as recycling (life-cycle assessment), finding that chains are controllable not through incineration prices and taxes but rather through regulatory instruments and covenants between the government and industry. Craighill and Powell (1996) proved that lifecycle evaluation is a powerful tool in sustainable waste management and recycling policy and that recycling systems should perform better than waste disposal systems in reducing global warming, and acidification effects.

The progression of DRW's life cycle is shown in Figure 1. The life length of DRW is T (shown as $[0, \mathrm{~T}]$ in Figure 1(a)) and can be divided into three stages: the container or commodity $([0, \mathrm{~A}))$, waste (DRW, $[\mathrm{A}, \mathrm{B})$ ) and recycled material $([\mathrm{B}, \mathrm{T}])$. The use time of DRW for each individual is $t$ (shown as $[0, t)$ in Figure 1(b)) and is the combination of two stages: container or commodity and recycled material. The remainder of the life cycle consists of waste time.

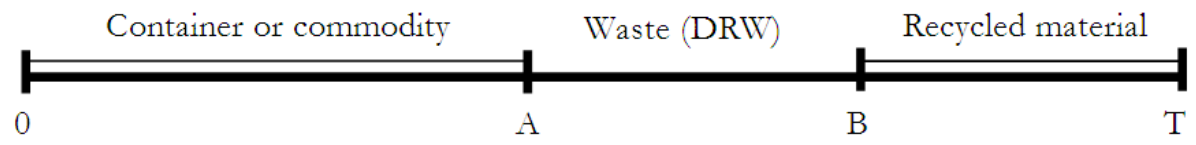

(a) The stages of DRW's life cycle

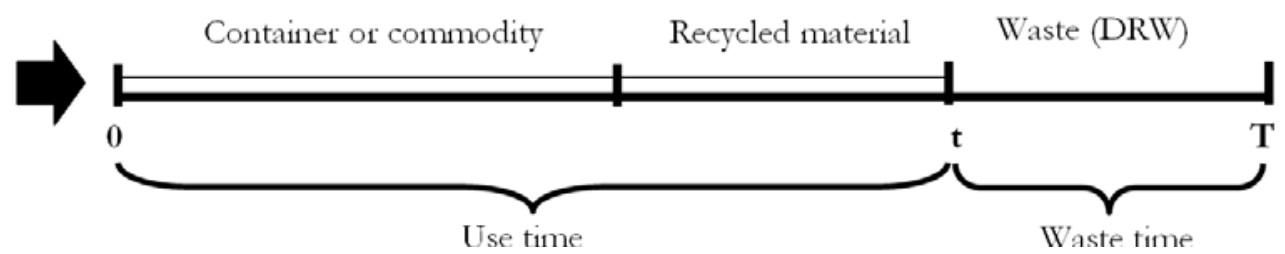

b) The use time and waste time of DRW's life cycle

Fig. 1. The life cycle of DRW

The monetary utility that each individual obtains over the life cycle of DRW by unit time is $u$, which is proportional to the environmental consciousness of every individual $(c)$, so $0<u=g(c)$. The individual utility obtained from DRW is $U$, which should be proportional to the magnitude of $u$ multiplied by $t$, so $0<$ $U=G(c, t)=\int_{0}^{t} u d x$ and $\partial G / \partial c>0, \partial G / \partial t>0$, $\partial^{2} G /(\partial c \partial t)=\partial^{2} G /(\partial t \partial c)>0, \quad \partial^{2} G /(\partial c)^{2}<0, \quad$ and $\partial^{2} G /(\partial t)^{2}<0$. This assumption can be proven by existing studies on individual preferences regarding recycling as one determinant of recycling behavior. Huhtala (2010) suggested that preferences play an important role in the willingness to contribute a public good. Kulshreshtha and Sarangi (2001) analyzed a model of a monopoly firm offering a refund to its heterogeneous consumers (consumers' preferences concerning recycling differ) in exchange for its used packages. These authors also showed that the price discrimina- tion of the firm could lead to socially suboptimal recycling behavior ${ }^{3}$.

The net individual utility of DRW for each individual $(\mathrm{W}(\mathrm{c}, \mathrm{t}))$ is a function of the WRF, the subsidy, individual monetary utility and the use time of DRW, where WRF (subsidy) is proportional to the use (waste) time of DRW and the Specific Relationship between WRF and subsidy exists. Therefore, this paper assumes that $W R F=\int_{0}^{t} H(x) d x$ and that

Subsidy $=\int_{t}^{T} K H(x) d x$, so

$W(c, t)=\int_{0}^{t}(u-H(x)) d x+\int_{t}^{T} K H(x) d x=$

\footnotetext{
${ }^{3}$ Because it has been empirically shown that the use time of DRW is proportional to the environmental consciousness of every individual, this model assumed that $\partial^{2} G /\left(\partial u_{i} \partial t\right)=\partial^{2} G /\left(\partial t \partial u_{i}\right)>0$.
} 
$G(c, t)-\int_{0}^{t} H(x) d x+\int_{t}^{T} K H(x) d x$, where $0<H(t)$, $K>0, \partial H / \partial t>0$ and $\partial^{2} H /(\partial t)^{2}<0$.

Every individual obtains the monetary utility, pays a WRF in the use time of a DRW container or commodity, and obtains a subsidy for the waste time. There is no difference in time preferences between individuals.

The decision problem concerning DRW is that individuals should choose the use time of DRW to maximize their net individual utility. This optimization can be described as follows:

$\operatorname{Max}_{t} W(c, t)=G(c, t)-\int_{0}^{t} H(x) d x+\int_{t}^{T} K H(x) d x$.

The solution on the first-order condition of (1) is

$\partial G\left(c, t^{*}\right) / \partial t=(K+1) H\left(t^{*}\right)$.

The meaning of (2) is that the marginal individual utility is equal to the sum of the marginal subsidy and the marginal WRF for the optimal use time. The second-order condition of (1) can be described as follows:

$\partial^{2} I U /(\partial t)^{2}=\partial^{2} G\left(c, t^{*}\right) /(\partial t)^{2}-(K+1)\left[\partial H\left(t^{*}\right) / \partial t\right]<0$.

Equation (3) represents the increasing rate of marginal utility, which is less than the sum of the increasing rate of the marginal subsidy and the marginal WRF at the optimal use time.

Lemma 1: A greater level of environmental consciousness of every individual leads to more use time for DRW.

Proof: The total derivative of (2) is:

$\left.\partial^{2} G\left(c, t^{*}\right) /(\partial t)^{2}\right] d t+\left.\left[\partial^{2} G\left(c, t^{*}\right) /(\partial t \partial c)\right] d c\right|_{t=t^{*}}=$

$(K+1)\left[\partial H\left(t^{*}\right) / \partial t\right] d t$

Following $\partial^{2} G /(\partial t \partial c)>0$ and (2),

$$
d t /\left.d c\right|_{t=t^{*}}=-\partial^{2} G /(\partial t \partial c) /\left\{\partial^{2} G\left(c, t^{*}\right) /(\partial t)^{2}-(K+1)\left[\partial H\left(t^{*}\right) / \partial t\right]\right\}>0 \text {. Q.E.D. }
$$

Lemma 2: A greater environmental consciousness of every individual increases net individual utility.

Proof: Differentiating (1) by $c$ produces

$$
\begin{aligned}
& \operatorname{Max}_{t} W(c, t)=G(c, t)-\int_{0}^{t} H(x) d x+\int_{t}^{T} K H(x) d x \\
& \partial W / \partial c=\partial G / \partial c+(\partial G / \partial t)(d t / d c)- \\
& (K+1)(\partial H / \partial t)(d t / d c) .
\end{aligned}
$$

Following $\partial G / \partial c>0$ and (1),

$$
\partial W /\left.\partial c\right|_{t=t^{*}}=\partial G /\left.\partial c\right|_{t=t^{*}}>0 \text {. Q.E.D. }
$$

From Lemma 1 and Lemma 2, we can conclude that the environmental consciousness of every individual is directly proportional to the use time and the net individual utility, which are similar to the results found by Georgiadis and Vlachos (2004). These authors used the applied system dynamics methodology to examine the impact of the green image effect, the take-back obligation and proper collection campaigns on product recovery behavior in the long term and found that the effect of product recovery on customer demand (which implies an increase in their individual utility) is more pronounced in cases where customers have more developed environmental consciousness and that this increase in environmental consciousness forces states to introduce more environmentally friendly policies (which should lead to higher use time). From Lemma 1, the use time of DRW is proportional to the environmental consciousness of every individual, so $t=f(c), \partial f / \partial c>0$. The dynamic adjustment function of the use time of DRW is: $t^{\prime}=d f(c) / d c=\eta, \eta>0$.

This assumption set for the government represents the government's ability to influence the dynamic adjustment relationship between every individual's environmental consciousness and the use time of DRW. For example, the government might adopt a more active (or inactive) incentive mechanism to promote a resource recycling program and provide convenient recycling channels.

From differentiating (2) with respect to $c$ and (4), the dynamic adjustment function of WRF is

$d H(t) / d c=\left\{\eta\left[\partial^{2} G /(\partial t)^{2}\right]+\partial^{2} G /(\partial t \partial c)\right\} /(K+1)$.

For the Specific Relationship, the dynamic adjustment function of the subsidy is:

$d[K H(t)] / d c=K\left\{\eta\left[\partial^{2} G /(\partial t)^{2}\right]+\partial^{2} G /(\partial t \partial c)\right\} /(K+1)$.

The subsidy for every individual $(I S(t))$ is $I S(t)=\int_{t(c)}^{T} K H(x) d x-\int_{0}^{t(c)} H(x) d x$; therefore, the dynamic adjustment function of the subsidy for every individual is:

$$
I S^{\prime}=\mathrm{dIS} / d c=-\eta(K+1) H(t) .
$$

The government does not know every individual's environmental consciousness, but it does know that for every individual $(\forall i), c_{i}$ is constant and $c_{i} \neq c_{j}$ when $i \neq j$ and that every individual's probability density function is: $\left\{c \mid \int_{\underline{c}}^{\bar{c}} v(\tau) d \tau=1, c \in[\underline{c}, \bar{c}]\right\}$, where 
$\underline{c}, \bar{c}$ are the lower and upper bounds of environmental consciousness and positivity. There are $N$ individuals, and the total subsidy $(T S(t))$ should be less than or equal to the budget of the government (which is $B$ (constant)), so the government's budget constraint is:

$$
T S(t)=N \int_{\underline{c}}^{\bar{c}} I S(t) v(\tau) d \tau \leq B .
$$

From (1) and the above assumptions, the social utility of DRW is $S U(c)$, and the government will choose the policy variable $(\eta)$ that optimizes the social utility of
DRW under the budget constraint and the above dynamic adjustment functions, which are based on every individual's optimal use time for DRW. This relationship exists because the government can control the dynamic adjustment function of DRW's use time, the WRF and the subsidy, and the subsidy of every individual. Therefore, the model used is:

$$
\underset{\eta}{\operatorname{Max}} \mathrm{SU}(c)=N \int_{\underline{c}}^{\bar{c}}[G(c, t)+I S(t)] v(\tau) d \tau .
$$

(9) is subject to (4), (5), (6), (7), and (8), and $t(\underline{c})$ and $t(\bar{c})$ are not constant.

The Hamiltonian function $(H F(t))$ is:

$$
\begin{aligned}
H F(t)= & N[G(c, t)+I S(t)] v(c)+\alpha \eta+[(\beta+\gamma K) /(K+1)]\left\{\eta\left[\partial^{2} G /(\partial t)^{2}\right]+\partial^{2} G /(\partial t \partial c)\right\} \\
& -\delta \eta(K+1) H(t)-\lambda N I S(t) v(c)
\end{aligned}
$$

where $\alpha, \beta, \gamma, \delta$, and $\lambda$ are the multipliers of (4), (5), (6), (7) and (8), respectively.

The necessary conditions of the Hamiltonian function are

$$
\begin{aligned}
& \partial H F / \partial \eta=\alpha+[(\beta+K \gamma) /(K+1)] \partial^{2} G /(\partial t)^{2}- \\
& \delta(K+1) H(t(c))=0 \\
& \alpha^{\prime}=-\partial H F / \partial t=-\{N[\partial G / \partial t-(1-\lambda)(K+1) H(t)] \\
& v(c)-\delta \eta \partial^{2} G /(\partial t)^{2}+[(\beta+\gamma K) /(K+1)] \\
& \left.\left[\eta\left(\partial^{3} G /(\partial t)^{3}\right)+\partial^{3} G /(\partial t \partial c \partial t)\right]\right\} \\
& \beta^{\prime}=\gamma^{\prime}=\delta \eta \\
& \delta^{\prime}=-N[(1-\lambda) v(c)] .
\end{aligned}
$$

From equation (13), we obtain Proposition 1 and Lemma 3, and if the government increases the subsidy for individuals whose environmental consciousness is $c$ by one dollar, the social utility of DRW will increase by $N[(1-\lambda) v(c)]$ dollars.

Proposition 1: $\delta(t)=-N(1-\lambda) V(c)$ when

$$
V(c)=\int_{\underline{c}}^{c} v(\tau) d \tau \text {. }
$$

Lemma 3: If the government increases the subsidy of the individual whose use time for DRW is less than or equal to $t(c)$ by one dollar, the social utility of DRW will increase by $N[(1-\lambda) V(c)]$ dollars.

Proof: The integration of (13) with respect to $c$ is:

\footnotetext{
${ }^{4}$ Differentiating (2) with respect to $t, d H(t) / d t=\left[\partial^{2} G /(\partial t)^{2}\right] /(K+1)$.

${ }^{5}$ The Kuhn-Tucker Condition is $\lambda\left[G-N \int_{c}^{\tau} I S(t) v(\tau) d \tau\right]=0$ when $\lambda \geq 0$. The Transversality Condition is: $\alpha(\bar{c})=\alpha(\underline{c})=\beta(\bar{c})=\beta(\underline{c})=\gamma(\bar{c})=\gamma(\underline{c})=\delta(\bar{c})=\delta(\underline{c})=0$.
}

$N(1-\lambda) \int_{c}^{c} v(\tau) d \tau=N(1-\lambda) V(c)=-\delta(t)$. Q.E.D.

In reality, individuals with more environmental consciousness will recycle or reuse DRW more voluntarily, so the subsidy should be more effective (in terms of time use or net social utility) for individuals with less environmental consciousness; this phenomenon provides one explanation for Lemma 3. Chen Chung-Chiang (2005) developed a model in which the government uses a subsidy to motivate voluntary recycling and concluded that households' environmental beliefs affect the effect of a subsidy on voluntary recycling (in the case of individuals with less use time for DRW).

From (2), (10), (11), (12), (13), (14), (15) and Proposition 1, we obtain Proposition 2, Proposition 3, Lemma 4 and Lemma 5. When $0<\lambda<1$, which indicates a greater subsidy, social utility increases, so the government will set a positive WRF and subsidy for DRW. However, when $\lambda \geq 1$, which implies a neutral or inverse relationship between the subsidy and social utility, the government will not set a positive WRF and subsidy for DRW.

Proposition 2:

$W R F=\int_{0}^{t(c)}(\lambda-1) V(c)(2 \eta+1)\left[\partial^{2} G /(\partial t)^{2}\right] /[(K+1) v(c)]$.

Proposition 3:

Subsidy $=\int_{t(c)}^{T} K(\lambda-1) V(c)(2 \eta+1)\left[\partial^{2} G /(\partial t)^{2}\right] /[(K+1) v(c)]$.

Proof: Differentiating (10) with respect to $t$ yields

$$
\begin{aligned}
& \alpha^{\prime}=-\left\{\left[\left(\beta^{\prime}+K \gamma^{\prime}\right) /(K+1)+\delta\right]\left[\partial^{2} G /(\partial t)^{2}\right]+\right. \\
& {[(\beta+K \gamma) /(K+1)]\left[\eta \partial^{3} G /(\partial t)^{3}\right.} \\
& \left.\left.+\partial^{3} G /(\partial t \partial c \partial t)\right]+\delta^{\prime}(K+1) H(t)\right\} .
\end{aligned}
$$


Given (12) and (13), (14) produces

$$
\begin{aligned}
& \alpha^{\prime}=-\delta(\eta+1)\left[\partial^{2} G /(\partial t)^{2}\right]-[(\beta+K \gamma) /(K+1)] \\
& {\left[\eta \partial^{3} G /(\partial t)^{3}+\partial^{3} G /(\partial t \partial c \partial t)\right]+N[(1-\lambda) v(c)](K+1) H(t) .}
\end{aligned}
$$

Following (2) and Proposition 1, subtracting (11) from (15) yields

$$
\begin{aligned}
& N(1-\lambda) V(c)(2 \eta+1)\left[\partial^{2} G /(\partial t)^{2}\right]+N(K+1) H(t) v(c)=0 \\
& \Rightarrow H(t(c))=(\lambda-1) V(c)(2 \eta+1)\left[\partial^{2} G /(\partial t)^{2}\right] /(K+1) v(c) \\
& \Rightarrow K H(t(c))=K(\lambda-1) V(c)(2 \eta+1)\left[\partial^{2} G /(\partial t)^{2}\right] /(K+1) v(c) \text { Q.E.D. }
\end{aligned}
$$

Lemma 4: The determinant of whether the government will set an WRF and subsidy is the multiplier of the budget constraint of the government $(\lambda)$ because $\operatorname{sign}[R R F]=\operatorname{sign}[\operatorname{Subsidy}]=\operatorname{sign}(1-\lambda)$.

Proof: Following Proposition 2, Proposition 3, $V(c)>0, \quad(K+1)>0, \quad \eta>0, \quad v(c)>0 \quad$ and $\partial^{2} G /(\partial t)^{2}<0$,

$\operatorname{sign}[R R F)]=\operatorname{sign}[\operatorname{Subsidy}]=\operatorname{sign}(1-\lambda)$. Q.E.D.

$N \int_{\underline{c}}^{\bar{c}}\left\{\left[\int_{t(\bar{c})}^{T} H(x) d x-\int_{0}^{t(\bar{c})} K H(x) d x\right]+\left[\int_{t(c)}^{t(\bar{c})} H(x) d x+\int_{t(c)}^{t(\bar{c})} K H(x) d x\right]\right\} v(\tau) d \tau \leq B$

Because the basic waste time budget $\left(B_{B}\right)$ is a constant,

$$
\begin{aligned}
& N\left\{\int_{\underline{c}}^{\bar{c}}\left[\int_{t(c)}^{t(\bar{c})} H(x) d x\right] v(\tau) d \tau+\int_{\underline{c}}^{\bar{c}}\left[\int_{t(c)}^{t(\bar{c})} K H(x) d x\right] v(\tau) d \tau\right\} \\
& \leq B-B_{B} .
\end{aligned}
$$

Given Lemma 1, Fubini's theorem, Proposition 2, and Proposition 3, (16) becomes

$$
\begin{aligned}
& N(\lambda-1)(2 \eta+1) \int_{\underline{c}}^{\bar{c}} V(\tau)(1-V(\tau))\left[\partial^{2} G /(\partial t)^{2}\right] / v(\tau) d \tau \\
& \leq B-B_{B} .
\end{aligned}
$$

When equality (17) holds, for $N>0,2 \eta+1>0$, $0 \leq V(c) \leq 1, \quad v(c)>0 \quad$ and $\partial^{2} G /(\partial t)^{2}<0, \quad \operatorname{sign}(1-\lambda)=$ $\operatorname{sign}\left(B-B_{B}\right)$, and the range of $\lambda$ can be determined by $\operatorname{sign}\left(B-B_{B}\right)$. When inequality (17) holds, the above conclusion should still stand only when $B-B_{B} \geq 0$ and $\lambda>1$. Because the government should be rational, it should not set $B-B_{B} \geq 0$ for $\lambda>1$ (doing so would decrease the social utility of a DRW container); therefore, the above conclusion should still stand.

For (17), Proposition 2 and Proposition 3, we can obtain Lemma 6, which proposes that the budget of the government is the determinant of the WRF and subsidy. When the government wants to use economic incentives to increase the individual's use time of DRW, the government must allow a higher budget. Therefore, it is difficult to let the government's budgeting of the recycling system for DRW self-finance under the assumption of the Specific Relationship.
Lemma 5: The WRF and subsidy for the individual with the lowest environmental consciousness $(\underline{c})$ approach to zero.

Proof: Given $V(\underline{c})=\int_{\underline{c}}^{\underline{c}} v(\tau) d \tau \rightarrow 0, \quad R R F \rightarrow 0$ and Subsidy $\rightarrow$ 0. Q.E.D.

Lemma 5 states that the government will set the lowest (not highest) WRF and subsidy for the individual with the lowest environmental consciousness. The explanation for this lemma is that the combination of the WRF and subsidy that satisfies budget constraints and the Specific Relation leads to the highest waste time for DRW.

Because the Specific Relation represents the government budget, this paper assumes that the government will divide the budget into two stages, including the basic waste time $(=T-t(\bar{c}))$ and the rest of the waste time $(=t(c)-t(\bar{c}))$, causing (11) to become

Lemma 6: The WRF and subsidy should be the same with the $\operatorname{sign}\left(B-B_{B}\right)$ under the assumption of the Specific Relationship.

Proof: When $B-B_{B}>0$, which means that the government provides not only the funding of the basic waste time but also that of the total waste time, $0<\lambda<1$. When $B-B_{B}=0$, which means that the government will only provide funding for the basic waste time, and $B-B_{B}<0$, which means that the budget of government will not meet the budget of basic waste time, $\lambda \geq 1$. Therefore, for Proposition 2 and Proposition 3, the WRF and subsidy should be:

$$
\left\{\begin{array}{lcc}
\text { WRF, Subsidy }>0 & 0<\lambda<1 & B-B_{B}>0 \\
\text { WRF, Subsidy } \leq 0 & \lambda \geq 1 & B-B_{B} \leq 0
\end{array}\right.
$$

Q.E.D.

When the government wants the WRF and subsidy to be zero, it treats the recycling process of DRW like a free market. If the government nonetheless wants to increase individuals' time use of DRW, then improvement of the least environmental consciousness of individual $(\underline{c})$ is the determinant. Meanwhile, if the government wants to self-finance $(B=0)$, the optimal WRF and subsidy should be reversed, indicating that every individual receives a subsidy for the use time of a DRW container or commodity and pays the WRF for the waste time. 


\section{The model with the externality of DRW}

The individual utility that every individual obtains from DRW is $U_{e}$, which should be inversely proportional to the past social externality of DRW; therefore, $0<U_{e}=G_{e}(c, t, E), \quad \partial G_{e} / \partial E<0$, $\partial^{2} G_{e} /(\partial c \partial E)<0, \partial^{2} G_{e} /(\partial t \partial E)<0$, and $\partial^{2} G /(\partial E)^{2}>0$.

This relationship is based on the assumption that the government does not know the externality of DRW for every individual but knows and announces the past social externality of DRW, which is $E$ (constant). Individuals will be unable to observe the externality of DRW, but they will be able to observe the past social externality of DRW.

Individuals' decision problem of DRW is to choose the time use of DRW to maximize their net individual utility $\left(\mathrm{W}_{\mathrm{e}}(\mathrm{c}, t, E)\right)$ under the assumption of the past social externality of DRW, the WRF and the subsidy. This problem is summarized as

$$
\underset{t}{\operatorname{Max}} \mathrm{W}_{\mathrm{e}}(\mathrm{c}, t, E)=G_{e}(c, t, E)-\int_{0}^{t} H(x) d x+\int_{t}^{T} K H(x) d x .
$$

The first-order condition and the second-order condition of (18) are similar to (2) and (3), and Lemma 1 and Lemma 2 stand with both the first-order condition and the second-order condition of (18). Therefore, even when there is an externality of DRW, a higher environmental consciousness of each individual increases the use time and net individual utility.

$$
\frac{\partial H F_{e}}{\partial E}= \begin{cases}N\left(\partial G_{e} / \partial E\right) v(c)+[(\beta+\gamma K) /(K+1)] & \\ \left\{\eta\left[\partial^{3} G_{e} /\left((\partial t)^{2} \partial E\right)\right]+\partial^{3} G_{e} /(\partial t \partial c \partial t)\right\}=0 & c \in[\underline{c}, \bar{c}) \\ & N\left(\partial G_{e} / \partial E\right) v(c)+[(\beta+\gamma K) /(K+1)] \\ \left\{\eta\left[\partial^{3} G_{e} /\left((\partial t)^{2} \partial E\right)\right]+\partial^{3} G_{e} /(\partial t \partial c \partial t)\right\}-\pi=0 & \end{cases}
$$$$
H F_{e}(t)=N\left[G_{e}(c, t, E)+I S(t)\right] v(c)+\alpha \eta+
$$$$
[(\beta+K \gamma) /(K+1)]\left\{\eta\left[\partial^{2} G_{e} /(\partial t)^{2}\right]\right.
$$$$
\left.+\partial^{2} G_{e} /(\partial t \partial c)\right\}-\delta \eta(K+1) H(t)-\lambda N I S(t) v(c)+
$$$$
\pi N e(t-t(c)) v(c)+\pi \varphi(\underline{c})+\pi[\varphi(\bar{c})-E],
$$

where $\pi$ represents the multipliers of $\varphi^{\prime}(c)$ and (21).

The necessary conditions are:

$$
\left.\left.\alpha=-\left\{M \partial G_{e} / \partial t-(1-\lambda)(K+1) H(t)\right] \nu(c)-\delta \eta \partial^{2} G_{e} /(\partial t)^{2}+[(\beta+\gamma K) /(K+1)]\left[\eta \partial \partial^{3} G_{e} /(\partial t)^{3}\right)+\partial^{3} G_{e} /(\partial t \partial \alpha \partial t)\right]-\pi N(\partial e / \partial t) \nu(c)\right\}
$$

The other necessary conditions are the same as in (12) and (13), so Proposition 1 and Lemma 3 can be proved by the same methods. The optimal formulas of the WRF and subsidy with the externality of DRW by the individuals whose use time for DRW is $t(c)$ (and whose environmental consciousness is $c$ ) should be obtained through Proposition 4 and Proposition 5, which are adapted from (19) and (20). Because $\pi<0$ and $\partial e / \partial t<0$, and from the comparison among Proposition 2, Proposition 3, Proposition 4, and Proposition 5, the WRF and subsidy would be greater with the externality of DRW than without the externality of DRW. However, Lemma 4 may stand under the assumption of the externality of DRW and the Specific Relationship. The proof for this relationship is that the $\operatorname{sign}[R R F]=\operatorname{sign}[$ Subsidy $]$ may not be equal to $\operatorname{sign}(1-\lambda)$.

Proposition 4: $W R F=\int_{0}^{t(c)}\left\{K(\lambda-1) V(c)(2 \eta+1)\left[\partial^{2} G_{e} /(\partial t)^{2}\right] /[(K+1) v(c)]+\pi(\partial e / \partial t) /(K+1)\right\}$.

Proposition 5: Subsidy $=\int_{t(c)}^{T}\left\{K(\lambda-1) V(c)(2 \eta+1)\left[\partial^{2} G_{e} /(\partial t)^{2}\right] /[(K+1) v(c)]+K \pi(\partial e / \partial t) /(K+1)\right\}$. 
Proposition 6 is the optimal solution of the multiplier for the dynamic adjustment function of the present social externality of DRW, where this multiplier was found to be negative. In addition, Lemma 7 states that the WRF and the subsidy for the individual with the least environmental consciousness, given the externality of DRW, would be greater than without the externality of DRW. Therefore, the reversal effect on the individual utility that every individual obtains from DRW is found by differentiating the present social externality of DRW.

Proposition 6: $\pi=N\left[\partial G_{e}(\bar{c}, t(\bar{c}), E) v(\bar{c})\right]<0$.

Proof: Proposition 4 and Proposition 5 can be proven by the same method. Given $\beta(\bar{c})=0, \gamma(\bar{c})=0$, $\partial G_{e} / \partial E<0$ and (21),

$\pi=N\left[\partial G_{e}(\bar{c}, t(\bar{c}), E) v(\bar{c})\right]<0$. Q.E.D.

Lemma 7: The WRF and subsidy for the individual with the least environmental consciousness $(\underline{c})$ are positive under the assumption of the externality of DRW and the Specific Relationship.

Proof: For $V(\underline{c})=\int_{c}^{\underline{c}} v(\tau) d \tau \rightarrow 0, \pi<0, \mathrm{~K}>0$ and $\partial e / \partial t<0$, so $F(t(c))=\pi(\partial e / \partial t) /(K+1)>0$ and

$S(t(c))=K \pi(\partial e / \partial t) /(K+1)>0$. Q.E.D.

Given Proposition 4 and Proposition 5, the twostage budget constraint of the government becomes:

$$
\begin{aligned}
& N(\lambda-1)(2 \eta+1) \int_{\underline{c}}^{\bar{c}} V(\tau)(1-V(\tau))\left[\partial^{2} G /(\partial t)^{2}\right] / v(\tau) d \tau \\
& +N \int_{\underline{c}}^{\bar{c}}[(1-V(\tau)) \pi(\partial e / \partial t)] d \tau \leq B-B_{B} .
\end{aligned}
$$

Given (21), the externality of a DRW container or commodity and the Specific Relationship of the WRF and subsidy, Lemma 6 is rejected, which indicates that the signs of the WRF, the subsidy and $\left(B-B_{B}\right)$ could not be determined within the range of $\lambda$.

From the above discussion, this model suggests that under current conditions, with the externality of DRW and the Specific Relationship, the WRF and subsidy should not be optimal. Therefore, the purposes of the WRF and subsidy are not achieved due to limitations posed by the Specific Relationship.

The reasons of the above results should be the different purposes of the WRF and subsidy, so they proved a life-cycle evaluation model of due recyclable waste (DRW) is necessary to analyze its optimal waste recycling fee (WRF) and subsidy. For the external cost of DRW will not be related to the external benefit of recyclable resources, the Specific Relation will not be suitable for the purposes of the
WRF and subsidy, and there are many problems that have been produced by the Specific Relation. For example, the Specific Relation in Taiwan is that the subsidy for DRW is equal to the amount yielded when multiplying the WRF by the ratio of the cost of non-human processes to the total cost, and then dividing this total by the estimated recycling ratio. Therefore, its present subsidy is equal to $4 / 3$ times of its $\mathrm{WRF}^{5}$.

The other problems of the Specific Relation include the equality of the WRF and subsidy and the lobbying cost of interest groups, among others. When the per-unit subsidy is held constant, the recycled weight of DRW increases, the total subsidy increases, and the amount of WRF levied due to the Specific Relation increases. However, this result is not fair for Designated Responsible Entities that are paying WRF despite trying their best to engage in recycling activities for their DRW. When the WRF per unit is held constant, the recycled weight of DRW increases, and the per-unit subsidy for the Specific Relation decreases. However, this condition remains unfair for those recycling enterprises that attempt to engage in recycling DRW. In Taiwan, an increasing number of Designated Responsible Entities paying the WRF challenge the targets and amounts of the WRF and subsidy through lobbying.

\section{Conclusion}

This study employed a life-cycle evaluation model to analyze the optimal WRF and subsidy with the Specific Relationship. The model used in this study assessed assumptions concerning the externality of DRW, the environmental consciousness of individuals and the balancing of budgets. The results suggest that the WRF and subsidy cannot be optimal and that the purposes of the WRF and subsidy are not achieved due to limitations posed by the Specific Relationship.

The results reveal that environmental consciousness concerning DRW is the most important exogenous variable necessary to foster higher use times; therefore, the government should work to increase individuals' environmental consciousness concerning DRW. This objective could be achieved with regular communication activities, which are particularly important for keeping community residents, municipal garbage collection teams, and recycling enterprises aware of and active in separating waste and participating in a DRW container or commodity

\footnotetext{
5 Subsidy $=R R F \times(100-20) \% / 60 \%$, where $20 \%$ is the ratio of the cost of human affairs to the total cost, and $60 \%$ is the estimated recycling ratio. The RRF is equal to the net recycling and treatment cost of DRW divided by the sales weight of containers and commodities.
} 
recycling program. From Stanisavljevic, et al. (2015), two important factors of a sustainable waste recycling program are the practice of communitybased recycling management system (CBR) and the benchmark learning of an integrated sustainable waste management.

The other important problem posed by the Specific Relationship is that the most effective recycling policy may not be a subsidy. A more effective recycling policy may take the form of the following instruments: product take-back mandates and recycling rate targets with or without a tradable recycling credit scheme, voluntary product take-back mandates with recycling rate targets, advance recycling fees (ARFs), ARFs combined with a recycling subsidy, landfill bans, "Pay as you discard" pricing for waste collection/disposal, recycling subsidies and recycling investment tax credits. Nestor (1992) used annual data from 1958-1987 to estimate the demand for old newspapers (an input to United States (US) newsprint production) and found that the most effective recycling policy would include the promotion of US newsprint production. Butler and Hooper (2005) suggested that the policies for reducing the impact of packaging waste in the UK should focus on production methods, particularly lightweighting. One impressive list of examples of lightweighting is that of the Industry Council for Packaging and the Environment (INCPEN, 2003), which promotes the reduction of the weight of materials for a given packaging size through redesign or material substitution. Walls (2006) proved that ARF combined with a recycling subsidy can achieve a socially optimal level of waste disposal, recycling and product recyclability.

Further studies could focus on the most effective recycling management policy possible for DRW recycling, consider the actual possibilities of DRW reuse and recycling (Vellini and Savioli, 2009) have a similar viewpoint), and discuss reforming recycling regulations by decoupling the WRF and subsidy or initiating programs supporting individuals' environmental consciousness. Such programs could influence the public through a series of public dis- cussions and hearings and promote individual environmental attitudes and behaviors that can achieve the objectives pursued through policies such as the WRF and subsidy (as similarly concluded by Chen Chung-Chiang (2005)).

Further studies could use the following two-stage game to prove the conclusion of this paper. First, the government announces the WRF $\left(F_{A}\right)$ and subsidy $\left(S_{A}\right)$, maximizing the social utility (given the budget constraint) without imposing any relationship between the WRF and subsidy. Second, given the announced WRF and subsidy, the consumer chooses the optimal use time of containers. Through backward induction, the subgame perfect equilibrium (SPE) can be achieved.

Because there is no relationship between WRF and subsidy, $\quad F_{A}=\int_{0}^{t} M_{A}(x) d x$ and $S_{A}=\int_{t}^{T} N_{A}(x) d x$, where $M_{A}(t), N_{A}(t), \mathrm{K}, \partial M_{A} / \partial t, \partial N_{A} / \partial t>0$, $\partial^{2} M_{A} /(\partial t)^{2}$ and $\partial^{2} N_{A} /(\partial t)^{2}<0$. The decision problem of a DRW container faced by individual i can be described as follows:

$\underset{t}{\operatorname{Max}} \mathrm{W}_{\mathrm{e}}(\mathrm{c}, t, E)=G_{e}(c, t, E)-\int_{0}^{t} M_{A}(x) d x+\int_{t}^{T} N_{A}(x) d x .(24)$

The marginal individual utility is equal to the sum of the marginal subsidy and the marginal WRF $\left(\partial G_{e}\left(c, t^{*}, E\right) / \partial \mathrm{t}=M_{A}\left(t^{*}\right)+N_{A}\left(t^{*}\right)\right)$.

The government's decision problem concerning DRW can be described as follows:

$$
\begin{aligned}
& \underset{M_{A}(x), N_{A}(x)}{\operatorname{Max}} \operatorname{SU}_{\mathrm{e}}(c)= \\
& N \int_{\underline{c}}^{\bar{c}}\left[G_{e}(c, t, E)+\int_{t(c)}^{T} N_{A}(x) d x-\int_{0}^{t(c)} M_{A}(x) d x\right] v(\tau) d \tau,
\end{aligned}
$$

subject to $\partial G_{e}\left(c, t^{*}, E\right) / \partial \mathrm{t}=M_{A}\left(t^{*}\right)+N_{A}\left(t^{*}\right) \quad$ and $N \int_{\underline{c}}^{\bar{c}}\left[\int_{t(c)}^{T} N_{A}(x) d x-\int_{0}^{t(c)} M_{A}(x) d x\right] v(\tau) d \tau \leq B$.

By examining the SPE, the optimal WRF and subsidy should be explored even though they are not linear.

\section{References}

1. Butler, J. and P. Hooper. (2005). Dilemmas in Optimising the Environmental Benefit from Recycling: A Case Study of Glass Container Waste Management in the UK, Resources, Conservation and Recycling, 45(4), pp. 331-355.

2. Chen Chung-Chiang. (2005). An Evaluation of Optimal Application of Government Subsidies on Recycling of Recyclable Waste, Polish Journal of Environmental Studies, 14(2), pp. 143-150.

3. Cheng Hui-Wen, Deng-Yang Chou and Wei-Chuan Yang. (2009). A Study on the Policy Effects of Extended Producer Responsibility Beverage Container Recycling Policy in Taiwan, Academia Economic Papers, 37(4), pp. 625-659.

4. Craighill, A.L. and J.C. Powell. (1996). Lifecycle Assessment and Economic Evaluation of Recycling: A Case Study, Resources, Conservation and Recycling, 17(2), pp. 75-96.

5. EEA. (2009). Diverting waste from landfill - Effectiveness of waste-management policies in the European Union. 
6. ETC/RWM. (2008). Evaluation of waste policies related to the Landfill Directive, The Flemish Region, ETC/ RWM working paper $5 / 2008$.

7. Georgiadis, P. and D. Vlachos. (2004). The Effect of Environmental Parameters on Product Recovery, European Journal of Operational Research, 157(2), pp. 449-464.

8. Gupt, Y. and S. Sahay. (2015). Review of Extended Producer Responsibility: A Case Study Approach, Waste Management and Research, 33(7), pp. 595-611.

9. Hodge, M., J. Ochsendorf and J. Fernández. (2010). Quantifying Potential Profit from Material Recycling: A Case Study in Brick Manufacturing, Journal of Cleaner Production, 18(12), pp. 1190-1199.

10. Huang Wei-Lung. (2001). The Subsidy Mechanism of Waste Motorcycle-Tire Recycling, Taipei Economic Inquiry, 37(2), pp. 115-140.

11. Huhtala, A. (2010). Income Effects and the Inconvenience of Private Provision of Public Goods for Bads: The Case of Recycling in Finland, Ecological Economics, 69 (8), pp. 1675-1681.

12. INCPEN. (2003). Packaging reduction - doing more with less.

13. Kleineidam, U., A.J.D. Lambert, J. Blansjaar, J.J. Kok, and R.J.J. van Heijningen. (2000). Optimising Product Recycling Chains by Control Theory, International Journal of production Economics, 66(2), pp. 185-195.

14. Kulshreshtha, P. and S. Sarangi. (2001). No Return, No Refund: An Analysis of Deposit Refund Systems, Journal of Economic Behavior and Organization, 46 (4), pp. 379-394.

15. Moore, W.K. and D.L. Scott. (1983). Beverage Container Deposit Laws: A Survey of the Issues and Results, The Journal of Consumer Affairs, 17(1), pp. 57-80.

16. Naughton, M., F. Sebold and T. Mayer. (1990). The Impacts of the California Beverage Container Recycling and Litter Reduction Act on Consumers, The Journal of Consumer Affairs, 24(1), pp. 190-220.

17. Nestor, D.V. (1992). Partial Static Equilibrium Model of Newsprint Recycling, Applied Economics, 24(4), pp. 411-417.

18. Nnorom, I.C. and O. Osibanjo. (2008). Overview of Electronic Waste (E-Waste) Management Practices and Legislations, and Their Poor Applications in the Developing Countries, Resources, conservation and recycling, 52(6), pp. 843-858.

19. Porter, R.C. (1983). Michigan's Experience with Mandatory Deposits on Beverage Containers, Land Economics, 59(2), pp. 177-194.

20. Stanisavljevic, N., S. Vujovic, M. Zivancev, B. Batinic, B. Tot, and D. Ubavin. (2015). Application of MFA as a Decision Support Tool for Waste Management in Small Municipalities - Case Study of Serbia, Waste Management and Research, 33(6), pp. 550-560.

21. Vellini, M. and M. Savioli. (2009). Energy and Environmental Analysis of Glass Container Production and Recycling, Energy, 34(12), pp. 2137-2143.

22. Walls, M. (2006). EPR Policies and Product Design: Economic Theory and Selected Case Studies, Resources for the Future, Washington, DC: OECD, pp. 1-40.

23. Walls, M. (2011). Deposit-refund systems in practice and theory, Washington, DC: OECD, Resources for the Future, pp. 11-47.

24. Yeh Chi-Kai and Daigee Shaw. (2004). An Effective Approach for Hazardous Waste Management: Performance Bond System, Taiwanese Agricultural Economic Review, 10(1), pp. 25-58. 